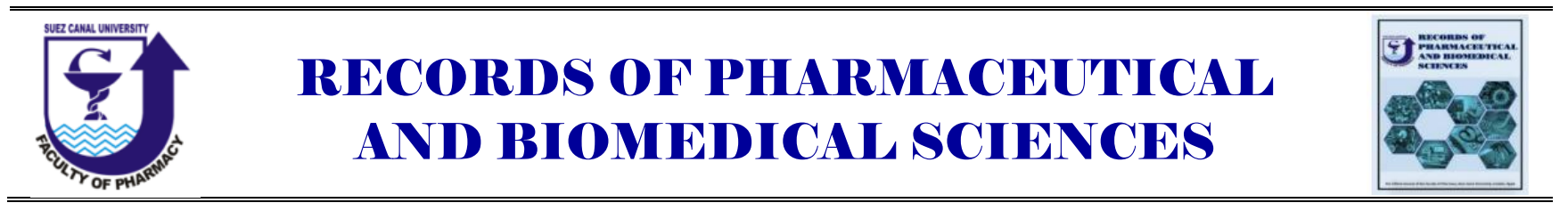

\title{
Monitoring of Organophosphorus and Organochlorine Pesticides Residues in Freshwater of Suez Canal Region, Egypt by Gas Chromatography
}

\author{
Mohamed A. Abdel Shakour*a ${ }^{* a}$ Randa A. Abdel Salam ${ }^{\text {b }}$, Ghada M. Hadad ${ }^{\text {b }}$, Diaa T. A. Youssef ${ }^{c}$ \\ ${ }^{a}$ Forensic Medicine Administration, Ministry of Justice, Ismailia, Egypt, ${ }^{b}$ Department of Pharmaceutical \\ Analytical Chemistry, Faculty of Pharmacy, Suez Canal University, Ismailia, Egypt, ${ }^{c}$ Department of \\ Pharmacognosy, Faculty of Pharmacy, Suez Canal University, Ismailia, Egypt
}

Received on: 13.10. 2018

Revised on: 19. 11. 2018

Accepted on: 25. 11. 2018

Correspondence Author:

Tel: +201221329641

E-mail address:

dr_megypt@yahoo.com

\begin{abstract}
Water is very essential for the human, animal and agriculture existence. Water supplies are exposed to contamination by different sources from industrial, pharmaceutical, agricultural and natural origins. Traditionally, analytical methods based on gas chromatography or liquid chromatography were used to monitor water quality. The objective of this research was to monitor some OPPs and OCPs pesticides residues in Ismailia freshwater canal in the three governorates (Ismailia, Port Said and Suez) over a period started from May 2008 to January 2011 by GC using flame photometric detector (FPD) for OPPs and electron capture detector for OCPs pesticides. No OCPs pesticides residues were found in freshwater at quantification level of the GC method, however OPPs pesticides methamidophos (1.97 ngL-1) and ethoprophos (1.73 ngL-1) were detected in freshwater samples collected from Port Said governorate in February 2009.
\end{abstract}

Keywords: Pesticides; Freshwater; Suez Canal Region.

\section{Introduction}

The use of pesticides has greatly increased with the development of intensive agricultural practices, a consequence, the number of organic compounds being detected in surface or groundwater has raised concern about raw water contamination. These pollutants, present in water resources at low concentrations, can affect ecosystems and impact drinking water supplies. Ismailia freshwater canal is mainly affected by inputs of agricultural pollutants and to a lesser extent by urban and industrial activities. As water drains from the canal catchments area it could transports residues of a variety of toxic chemical products, some of which could cause ecological damage.
The complex matter of pesticide trace analysis can be afforded by developing / using multi-component methods able to determine as many as possible pesticides and pesticide metabolites having a broad range of polarity and structural properties in a wide array of sample matrices at the required sensitivity limit. Today, gas chromatography (GC) still remains the most popular technique for accomplishing multicomponent methods, as demonstrated by an effective identification /confirmation tool. The literature survey revealed that Gas chromatography (GC) and GC-MS has traditionally been the methods of choice for the analysis of organophosphorus pesticides (OPPs) in water samples (Serrano et al., 2012; Akdoğan et al., 2011; Fang et al., 2012; Samadi et al., 2012; Yang et al., 
2011; Camino-Sánchez et al.,2011; Alves et al., 2011; Portolés et al.,2011; Toledano et al.,2010; Jurzik et al., 2010; Huang et al., 2010; LópezBlanco et al.,2005)and for analysis of organochlorine pesticides (OCPs) (Beamer et al., 2012; Dasgupta et al.,2011; He et al., 2011; Mawussi et al., 2009; Kumari et al., 2008; Brondi et al., 2005; Wasswa et al., 2011; Chen et al., 2011; Jan et al., 2009; Portolés et al., 2010; Tahboub et al., 2005). The objective of this research was to monitor some OPPs and OCPs pesticides residues in Ismailia freshwater canal samples by GC using flame photometric detector (FPD) for OPPs and electron capture detector for OCPs pesticides.

\section{Experimental}

\subsection{Materials and Reagents}

The authentic standards of thirteen OPPs pesticides standards (Dichlorovos, methamidophos, ethoprophos , dimethoate, chloropyrifos-me, malathion, chlorpyrifos, phenthoate,prothiophos, profenophos, ethion, triazophos and azinophos-ethyl)and thirteen OCPs $(\alpha, \beta$ and $\Delta-$ benzenehexachloride (BHC) , heptachlor, aldrine, heptachlor epoxide, $\gamma-$ chlordane, endosulfan, dieldrin, $\mathrm{p}, \mathrm{p}^{\prime}$ Dichlorodiphenyl dichloro-ethylene ( $p, p^{\prime}$ DDE), endrin, $p, p^{\prime}$ Dichlorodiphenyldichloroethane ( $p, p^{\prime}$ DDD), $\mathrm{p}, \mathrm{p}^{\prime}$-Dichlorodiphenyltrichloroethane ( $\mathrm{p}, \mathrm{p}^{\prime}$ DDT)), were purchased from Accustandards Co. (New Haven, Connecticut, USA). Florisil (BDH, 60-100 U.S. mesh, England) activated at $130 \mathrm{oC}$ for 16 hours before use. Methanol and acetonitrile were (BDH, Poole, UK). Sodium Chloride and anhydrous sodium sulphate (ADWIC, Egypt), nhexane, chloroform, dichloromethane were analytical grade.

\subsection{GC method}

The Gas Liquid Chromatography Processes for OPPs and OCPs were conducted in the "Central Agricultural Pesticides Laboratory", Ministry of Agriculture and Land Reclamation, located in Dokki, Cairo as follows:

\subsubsection{GC for organophosphorus pesticides}

A Hewlett Packard, model HP 6890 gas liquid chromatograph equipped with flame photometric detector (FPD) was used to monitor residues of OPPs. The column was DB-5 (30 m length, 0.32 $\mathrm{mm}$ i.d. $\mathrm{x} 0.52 \mu \mathrm{m}$ film thickness). Injector temperature was held at $225{ }^{\circ} \mathrm{C}$ and detector temperature was held at $280{ }^{\circ} \mathrm{C}$. Nitrogen was used as a carrier gas running at a flow rate of $3 \mathrm{~mL} \mathrm{~min}^{-1}$. Column temperature program was as follows: initial temperature $90{ }^{\circ} \mathrm{C}$ held for $2 \mathrm{~min}$., elevated at a rate of $20^{\circ} \mathrm{C} \mathrm{min}{ }^{-1}$. The final temperature was $150{ }^{\circ} \mathrm{C}$, then raised at a rate of $6{ }^{\circ} \mathrm{C} \mathrm{min}^{-1}$. The final temperature was $270{ }^{\circ} \mathrm{C}$ for $15 \mathrm{~min}$.

\subsubsection{GC for organochlorine pesticides}

A Hewlett Packard gas liquid chromatograph equipped with $63 \mathrm{Ni}$ electron capture detector (ECD) was used to monitor residues of OCPs. A capillary column PAS-5 (25 m, i.d. $0.32 \mathrm{~mm}, 0.52 \mathrm{~mm}$ film thickness) was used. Injector temperature was held at $225^{\circ} \mathrm{C}$. The temperature program was as follows: initial temperature $90{ }^{\circ} \mathrm{C}$ held for $10 \mathrm{~min}$., then the temperature was raised at a rate of $6{ }^{\circ} \mathrm{C} \mathrm{min}{ }^{-1}$. The final temperature was $270{ }^{\circ} \mathrm{C}$ and held for $25 \mathrm{~min}$. Nitrogen was used as a carrier gas and make up gas

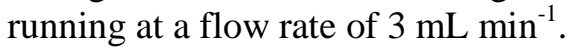

\subsection{Standard solutions and calibration}

Stock standard solutions of the selected OCPs and OPPs pesticides were prepared separately by dissolving $1 \mathrm{mg}$ of each compound in $10 \mathrm{~mL}$ hexane: acetone mixture (9:1). These stock solutions were stored at $4{ }^{\circ} \mathrm{C}$, protected from light.

\subsubsection{Calibration of GC method}

The standard solutions were prepared by further dilutions of the stock standard solutions with hexane to reach the concentration range of $0.01-10 \mathrm{mgL}^{-1}$ for the studied OPPs and OCPs pesticides. All the standard solutions were stored at $4{ }^{\circ} \mathrm{C}$ in the dark.

\subsection{Sampling}

Water samples from both freshwater and drinking water reservoir tanks were collected 15-20 centimeter depth at the selected sites in Ismailia, Port Said and Suez. The samples were collected bimonthly in 1-L capacity, glass, with TFE-lined screw caped bottles. Sampling bottles were rinsed three times with tap water, once with chromic acid, three times with organic-free water, twice with washing acetone, once with special grade acetone, twice with pesticide grade hexane and dry (uncapped) in a hot air oven at $360{ }^{\circ} \mathrm{C}$. Sampling bottles were washed three times with the sample then samples collected and preserved in cool ice boxes throughout the field trip and during transportation to the laboratory. 17 samples were collected from each site during the research period. 


\subsection{Sample preparation}

Sample was shacked and accurately $1 \mathrm{~L}$ was transferred to a $2 \mathrm{~L}$ separatory funnel, then $10 \mathrm{~mL}$ of saturated sodium chloride was added. Sample bottle was rinsed with $60 \mathrm{~mL}$ of $15 \%$ methylene chloride in hexane and the solvent was poured to the separatory funnel. The sample was shacked vigorously for $5 \mathrm{~min}$ and was allowed to separate for $10 \mathrm{~min}$. Organic layer was filtered through anhydrous sodium sulfate while the aqueous phase was returned back to the sampling bottle. The same procedure repeated three times. The organic solvent was evaporated and the residues were dissolved in $50 \mathrm{~mL}$ of chloroform. Sample cleanup done by transferring the extract to florisil columns, each containing 4 inches of florisil and 1 inch of anhydrous sodium sulfate. The columns eluted with $200 \mathrm{~mL} 15 \%$ methylene chloride in hexane. The collected solutions evaporated at 40 ${ }^{\circ} \mathrm{C}$ to dryness, and the residues brought-up in 10 $\mathrm{mL}$ acetone prior to analysis.

$3 \mu \mathrm{L}$ of the extracted solution were injected into GC-FPD, GC-ECD. Identification of the unknown peaks in the samples chromatograms was managed by comparison of sample retention time (Rt) with that of the corresponding pure standard compounds for GC method.

\section{Results and discussion}

The pesticides studied in this chapter include several types of compounds (OPPs and OCPs pesticides), so it is not possible to detect all the elements simultaneously in one GC run, so it was necessary to use more than one kind of detector to achieve selective and/or highly sensitive detection of these compounds. The determination of sulfur or phosphorus containing compounds is the job of the flame photometric detector (FPD), which is the detector of choice for separation of the studied OPPs, Fig. 1 represents complete separation of OPPs standards (Dichlorovos, methamidophos, ethoprophos , dimethoate, chloropyrifos-me, malathion, chlorpyrifos, phenthoate,prothiophos, profenophos,ethion, triazophos and azinophosethyl pesticides). Electron Capture Detector or GC-ECD is a technique used to analyze halogenated compounds and is primarily used in the environmental, forensic and pharmaceutical analysis. Within an ECD, when certain molecules pass by the detector, they capture some of the electrons in the sample and this reduces the current measured. The compensation for this reduction is recorded as a positive peak. ECD is used for the determination of OCPs and gives complete separation with reasonable retention time and selectivity for $\alpha$-BHC $\beta$-BHC and $\Delta$ - BHC, heptachlor, aldrine, heptachlor epoxide, $\gamma$-chlordane, endosulfan, dieldrin, $\quad \mathrm{p}, \mathrm{p}^{\prime}$ DDE, endrin, p,p' DDD and p,p' DDT (Fig. 2).

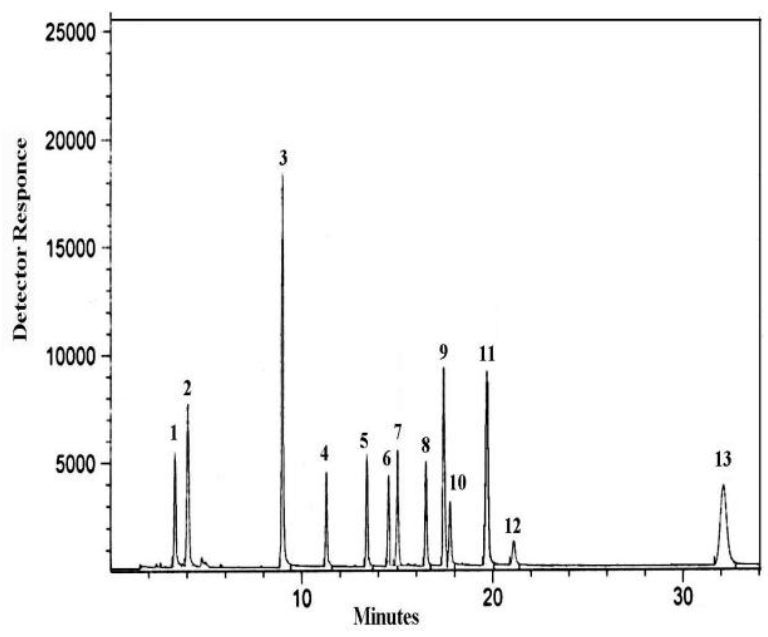

Fig. 1: GC/ FPD chromatogram of 1) Dichlorovos ,

2) methamidophos, 3) ethoprophos , 4) dimethoate, 5) chloropyrifos-me, 6) malathion, 7) chlorpyrifos, 8)phenthoate, 9) prothiophos, 10) profenophos,

11) ethion, 12) triazophos and

13) azinophos-ethyl pesticides.

Although the traditional liquid- liquid extraction (LLE) requires the handling of a large volume of chlorinated solvents and tends to be difficult to automate, the nature of the environmental sample can determine the choice between LLE and SPE methods. The analysis of wastewater and surface water requires the treatment of the total sample, including pesticides adsorbed on fine materials. LLE should be then preferred since the total sample can be handled without filtration.

Many solvents were used for extracting OPPs and OCPs pesticides, such as chloroform, nhexane, dichloromethane, and ethyl acetate. It was found that mixture of dichloromethane in $\mathrm{n}$-hexane is a better extraction solvent than the others. Also the ratio of dichroromethane to nhexane was studied and the better recovery percent for the analyzed pesticides was found to be $15 \%$ dichroromethane in $n$-hexane.

The LLE is followed by clean up on florisil column which is composed of a hard powdered 


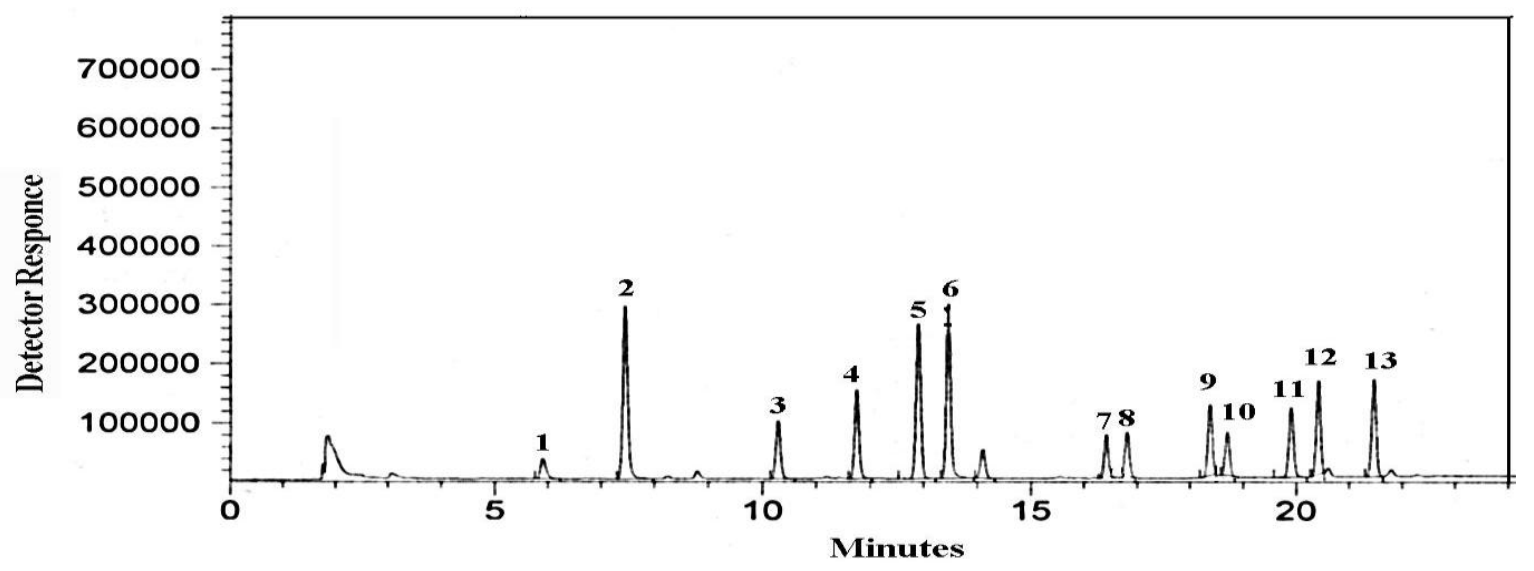

Fig. 2: GC/ ECD chromatogram of 1) $\alpha$-BHC , 2) $\gamma$-BHC 3) $\Delta$-BHC, 4) heptachlor, 5) aldrine, 6) heptachlor epoxide, 7) $\gamma$-chlordane, 8) endosulfan, 9) dieldrin, 10) p,p' DDE, 11) endrin, 12) p,p' DDD and 13) p,p' DDT.

magnesia-silica gel, It is often referred to as "activated magnesium silicate" and anhydrous sodium sulfate. As a highly selective adsorbent frequently employed in cleanup of pesticide residues and purification of chlorine-containing pesticides.

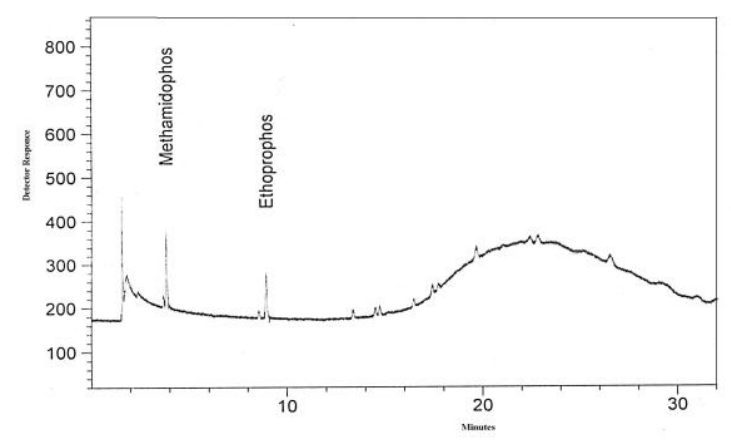

Fig. 3: GC/FPD chromatogram of freshwater sample collected from Port Said governorate in February 2009

The described GC method has been successfully employed to determine the most utilized OPPs and OCPs pesticides in freshwater and drinking water in the three governorates (Ismailia, Port Said and Suez) over a period started from May 2008 to January 2011. No OCPs pesticides residues were found in freshwater at quantification level of the GC method, however OPPs pesticides methamidophos $\left(1.97 \mathrm{ngL}^{-1}\right)$ and ethoprophos $\left(1.73 \mathrm{ngL}^{-1}\right)$ were detected in freshwater samples collected from Port Said governorate in February 2009 (Fig.3).

\section{Conclusion}

The performed GC method using two types of detectors FPD and ECD with simple liquid -liquid extraction conjunction offers a simple and sensitive approach for the simultaneous determination of OPPs and OCPs, which may be present in surface water samples due to excessive and misused handling of pesticides in Egypt.

\section{References}

Akdoğan A, Divrikli U, Elçi L. J AOAC Int. 2011; 94: 1882-1890.

Alves AC, Gonçalves MM, Bernardo MM, Mendes BS. J Sep Sci. 2011; 34: 1326-1332.

Beamer PI, Luik CE, Abrell L, Campos S, Martínez ME, Sáez AE. Environ Sci Technol. 2012; 46: 9055-9061.

Brondi SH, Spoljaric FC, Lanças FM. J Sep Sci. 2005; 28: 2243-2246.

Camino-Sánchez FJ, Zafra-Gómez A, Pérez-Trujillo JP, Conde-González JE, Marques JC, Vílchez JL.Chemosphere. 2011; 84: 869-881.

Chen W, Jing M, Bu J, Ellis Burnet J, Qi S, Song Q, Ke Y, Miao J, Liu M, Yang C. Environ. Monit. Assess. 2011; 177:1-21.

Dasgupta S, Banerjee K, Utture S, Kusari P, Wagh S, Dhumal K, Kolekar S, Adsule PG. J Chromatogr. A. 2011; 1218: 6780-6791.

Fang G, Chen W, Yao Y, Wang J, Qin J, Wang S. J Sep Sci. 2012; 35: 534-540. 
He H, Hu GJ, Sun C, Chen SL, Yang MN, Li J, Zhao Y, Wang H. Environ. Sci. Pollut. Res. Int. 2011; 18: 638-648.

Huang Y, Zhou Q, Xiao J, Xie G. J Sep Sci. 2010; 33(14): 2184-2190.

Jan MR, Shah J, Khawaja MA, Gul K. Environ. Monit. Assess. 2009; 155: 31-38.

Jurzik L, Hamza IA, Puchert W, Uberla K, Wilhelm M. Int J Hyg Environ Health. 2010; 213: 210-216.

Kumari B, Madan VK, Kathpal TS. Environ. Monit. Assess. 2008; 136: 39-44.

López-Blanco C, Gómez-Alvarez S, Rey-Garrote M, Cancho-Grande B, Simal-Gándara J. Anal. Bioanal. Chem. 2005; 383: 557-561.

Mawussi G, Sanda K, Merlina G, Pinelli E. Food Addit Contam Part A Chem Anal Control Expo Risk Assess. 2009; 26: 348-354.

Portolés T, Pitarch E, López FJ, Hernández F. J Chromatogr A. 2011; 1218: 303-315.
Portolés T, Sancho JV, Hernández F, Newton A, Hancock P. J Mass Spectrom. 2010; 45: 926-936.

Samadi S, Sereshti H, Assadi Y.J Chromatogr A. 2012; 1219: 61-65.

Serrano R, Portolés T, Blanes MA, Hernández F, Navarro JC, Varó I, Amat F. Sci. Total Environ. 2012; 433: 161-168.

Tahboub YR, Zaater MF, Al-Talla ZA. J Chromatogr A. 2005; 1098: 150-155.

Toledano RM, Cortés JM, Andini JC, Villén J, Vázquez A. J Chromatogr A. 2010; 1217: 47384742.

van der Veen I, de Boer J.Chemosphere. 2012; 88: 1119-1153.

Wasswa J, Kiremire BT, Nkedi-Kizza P, Mbabazi J, Ssebugere P. Chemosphere. 2011; 82: 130-136.

Yang ZH, Liu Y, Lu YL, Wu T, Zhou ZQ, Liu DH. Anal Chim Acta. 2011; 706: 268-274. 